\title{
Student Voice in Transformation from Studying Engineering to Doing Engineering
}

\author{
Azeeem Unnisa ${ }^{1}$, Ayush Dwivedi ${ }^{2}$, Saikat Saha ${ }^{3}$ \\ ${ }^{123}$ Department of Electronics and Communication Engineering, Hyderabad Institute of Technology and Management \\ (HITAM), Gowdavelly(V), Medchal(M), Hyderabad-500048, India. \\ 1azeemunnisa.ece@hitam.org \\ 2ayushkumardwivedi@yahoo.com \\ ${ }^{3}$ saikats701@gmail.com
}

\begin{abstract}
In the current trend of engineering education we have suddenly reached a point where it has become a certificatethat veryfew engineerswould recommend you to take. This is more of a case for engineering students from private colleges. To tackle this issue in our college the senior students decided along with the faculty to introduce a few good practices among the freshers. The objective was to give the students an overview of doing engineering practically, that included ways to create active and practical environment to do engineering and how engineering should be learnt best. These ideas were collected from various student groups and implemented in a short 1 day workshop on "Doing Engineering" in two batches. Student role was a major factor in this workshop as they were supposed to voice their opinion, think, create, design, implement and finally build the chair after completion of the workshop.Instructor's major role was to guide the students on the basics of designing a chair and pointing out the realistic side of the real time application of the results. These small tasks were introduced as steps for transformation in the current rat race for getting more than just an engineering certificate by involving students for making projects in the first year itself instead of waiting for $3^{\text {rd }}$ and $4^{\text {th }}$ year. This task had some smaller objectives too that included the following but were not limited to them: project based learning, induce creativity, technical understanding, practical skills, thinking beyond the present what eyes can see and the ability to question established facts and norms.
\end{abstract}

Keywords: Doing engineering, Project based learning, practical learning, active learning, studying engineering.

\footnotetext{
Azeeem Unnisa ${ }^{1}$

${ }^{1}$ Department of Electronics and Communication Engineering, Hyderabad Institute of Technology and Management (HITAM), Gowdavelly(V), Medchal(M), Hyderabad-500048, India.

1azeemunnisa.ece@hitam.org
}

\section{Objective of the workshop}

A. To equip the students with variety of activities in doing engineering especially in Designing and Project Based Learning.

The students were first introduced to engineering and were then told the meaning of doing engineering. They received a small essence of doing engineering through a short video on active learning.

B. To equip the students with variety of activities in doing engineering especially in Designing and Project Based Learning.

To implement this, the students were given an activity to innovate and design a model chair with all their creativity put into the chair individually.

C. Preparing concept/mind map, designing worksheet and knowing learning gap.

This was the second phase of the workshop where the students were supposed to work in a team to design a chair and build it. They were shown a video to tell them the importance of team work that described how team work helps build stronger foundation structure and a superior final outcome. The students were taught how being in a team helped them carry themselves as well as their team members and cover up for the weak spots of fellow team mates.

\section{Resources}

Other than the human resources we had used very limited quantity of materials to help us get through the whole workshop for both batches combined together.

\begin{tabular}{|l|l|}
\hline \multicolumn{2}{|c|}{ Table 1.1Workshop details } \\
\hline Date & 30 December 2014 \\
\hline Number of Participants & 203 \\
\hline Resource Person & Azeem Unnisa \\
\hline
\end{tabular}




\begin{tabular}{|c|c|c|c|}
\hline \multicolumn{2}{|l|}{ Venue } & \multicolumn{2}{|c|}{ Seminar Hall, HITAM } \\
\hline \multicolumn{4}{|c|}{ Table1.2Materials list } \\
\hline Item & Quantity & Cost per unit & Total cost \\
\hline Chocolates & 50 & 5 & 250 \\
\hline Pencils & 1 box & 20 & 20 \\
\hline White paper & 1 Ream & 300 & 300 \\
\hline \multicolumn{3}{|r|}{ Total } & 570 \\
\hline
\end{tabular}

At the end of the workshop the students were asked to implement their ideas and build their chair that was to be exhibited on $26^{\text {th }}$, January 2015, as part of Independence Day celebration of INDIA.

\section{Schedule and Sample work}

A. Workshop schedule

Table2.Schedules

\begin{tabular}{|l|l|l|}
\hline $\begin{array}{c}\text { Workshop } \\
\text { Step }\end{array}$ & \multicolumn{1}{|c|}{ Topic } & \multicolumn{1}{|c|}{ Mode } \\
\hline Step1 & $\begin{array}{l}\text { Basic introduction to } \\
\text { "what engineering is?" }\end{array}$ & $\begin{array}{l}\text { Questions/Answer } \\
\text { session }\end{array}$ \\
\hline Step 2 & $\begin{array}{l}\text { Video on "what is } \\
\text { engineering" and "What } \\
\text { doe doing engineering } \\
\text { imply" }\end{array}$ & $\begin{array}{l}\text { Audio/Visual aid } \\
\text { session }\end{array}$ \\
\hline Step 3 & $\begin{array}{l}\text { Concepts of active } \\
\text { learning, old and new } \\
\text { paradigm of active } \\
\text { learning. }\end{array}$ & $\begin{array}{l}\text { Description andio/Video on } \\
\text { active learning }\end{array}$ \\
\hline Step 4 & $\begin{array}{l}\text { Activity 1-Indivdual } \\
\text { chair design }\end{array}$ & $\begin{array}{l}\text { Activity on paper } \\
\text { Step 5 }\end{array}$ \\
\hline & $\begin{array}{l}\text { Video on Team Work } \\
\text { and Activity 2 }\end{array}$ & $\begin{array}{l}\text { Audio/Videowith } \\
\text { activity }\end{array}$ \\
\hline Step6 & $\begin{array}{l}\text { of task implementation } \\
\text { and Exhibition }\end{array}$ & $\begin{array}{l}\text { Description and } \\
\text { Exhibiton }\end{array}$ \\
\hline
\end{tabular}

B. Sample Designs made by students

I. Activity 1

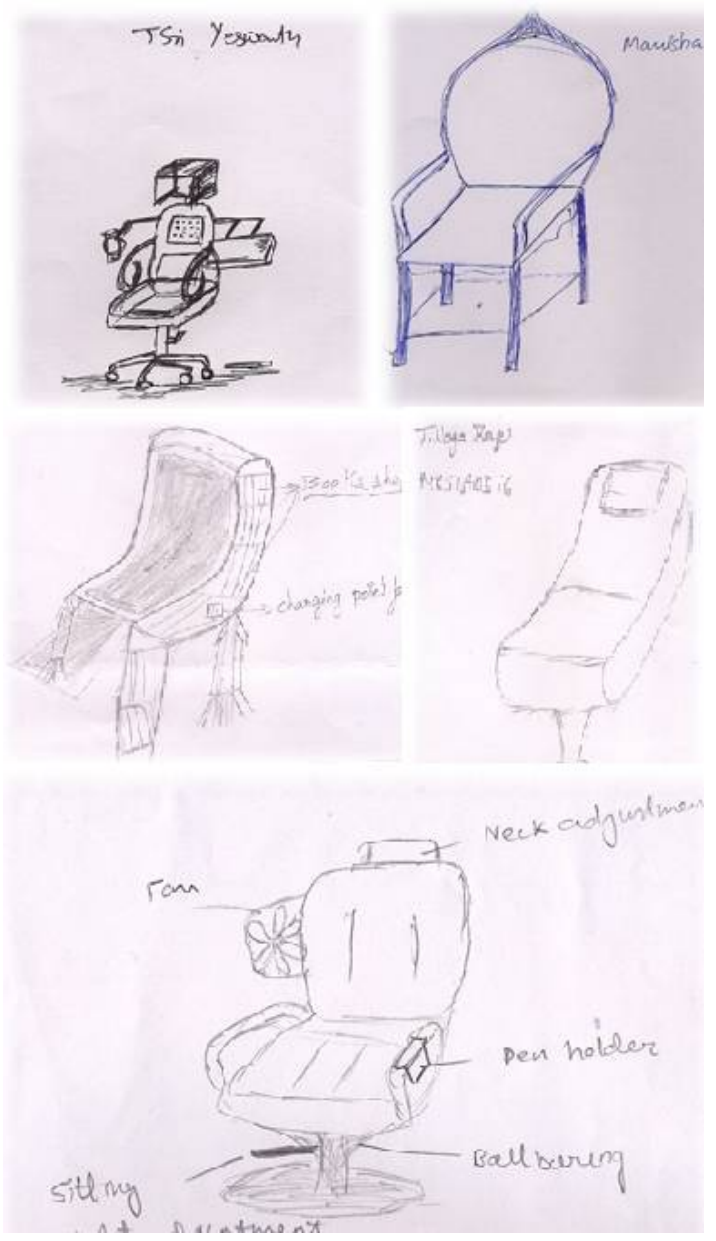

Figure 1:Some Results of activity 1

II. Activity 2 


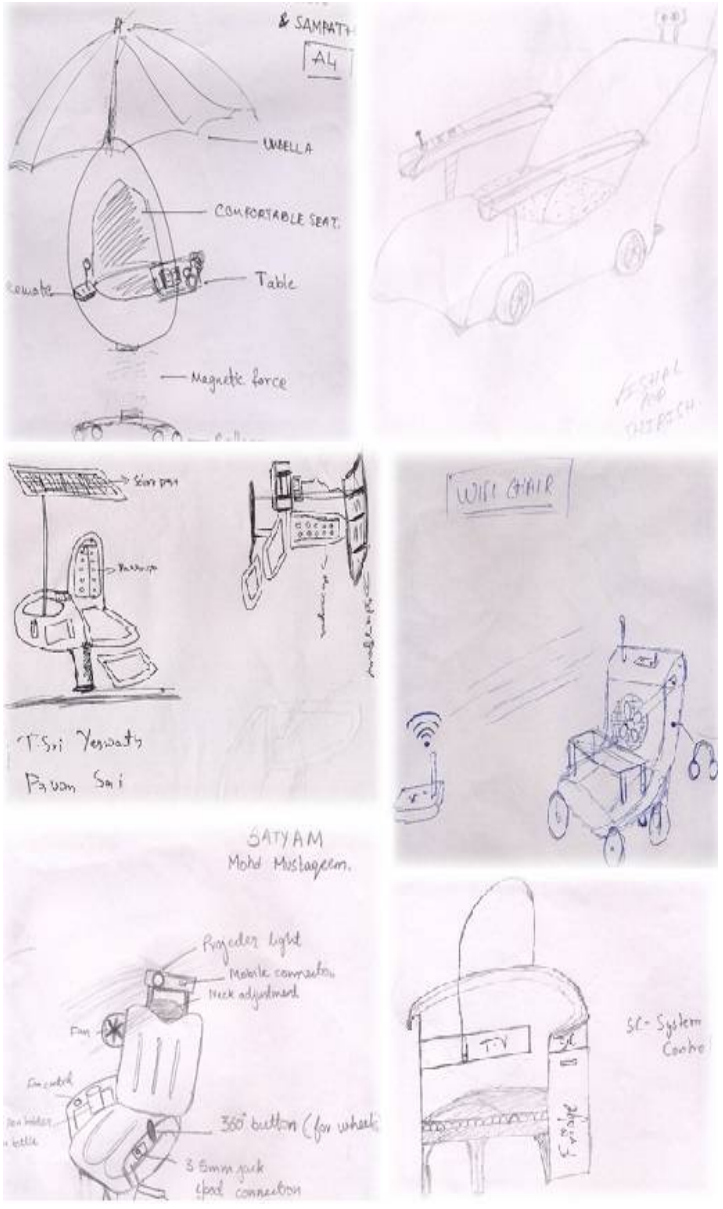

Figure 2: Some Results of activity 2

\section{Workshop 2}

An advanced level workshop was conducted later, where the students of $2^{\text {nd }}$ year were asked to come up with ideas for prototypes that would help generate energy. They were provided guidance by Assistant Professor Azeem Unnisa. Some of the prototypes were promising enough for realisation with some fine tunings.

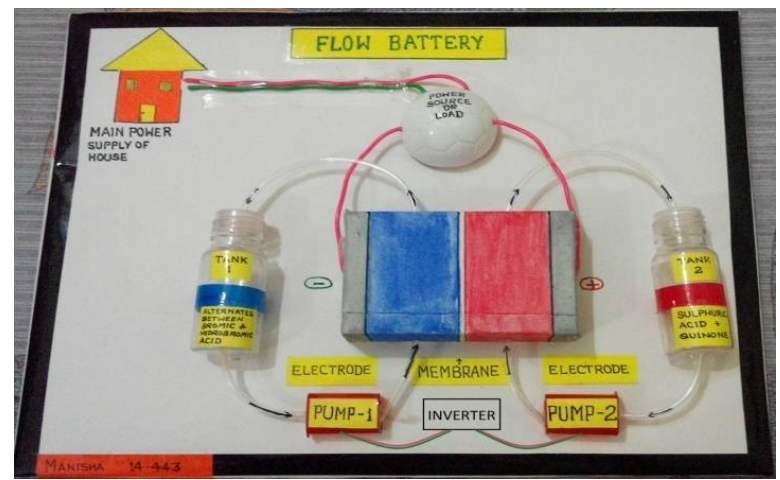

Figure 3.1: Flow battery made by $2^{\text {nd }}$ year students

The prototypes were evaluated by the Head of the Department of ECE and the Principal of the institution and the students were given valuable guidance and inputs to improvise on their prototype models. This workshop's idea was to adjust the student thinking towards their branch and design within set boundaries.

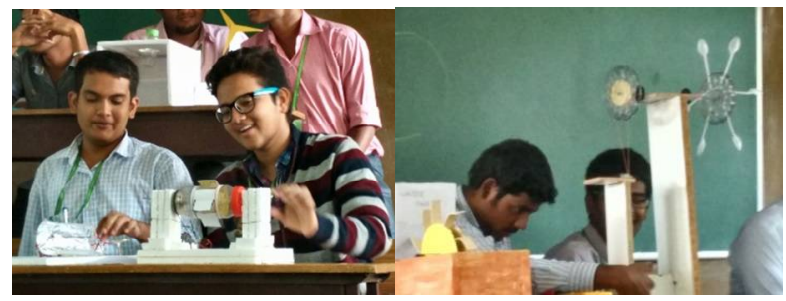

Figure 3.2: Some of the models designed at the workshop

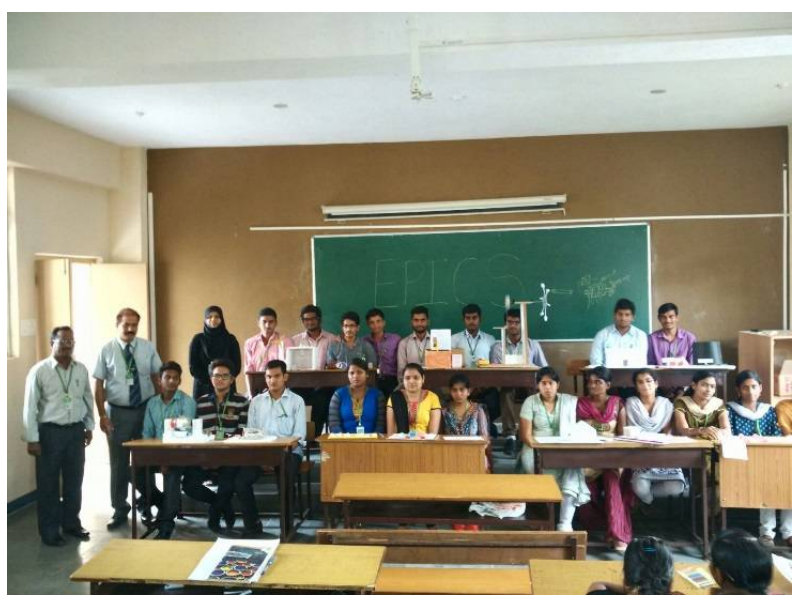

Figure 3.3: Group photo of participants their models and the guides.

\section{Results}

A. Student Feedback

A total of 203 students participated in the workshop 1 and about 80 in workshop 2. Feedback on the workshop's relevance and usefulness were taken from participating students on a five point scale - Excellent:5, Very Good:4, Good:3, Fair:2, Poor:1.

Table3. Response Count 


\begin{tabular}{|c|c|c|}
\hline S.No. & Response & $\begin{array}{c}\text { No. of Students } \\
\text { Rated }\end{array}$ \\
\hline 01 & Excellent & 165 \\
\hline 02 & Very Good & 88 \\
\hline 03 & Good & 16 \\
\hline 04 & Fair & 11 \\
\hline 05 & Poor & 00 \\
\hline
\end{tabular}

B. Statistical analysis

\section{Statistical Analysis of Responses}

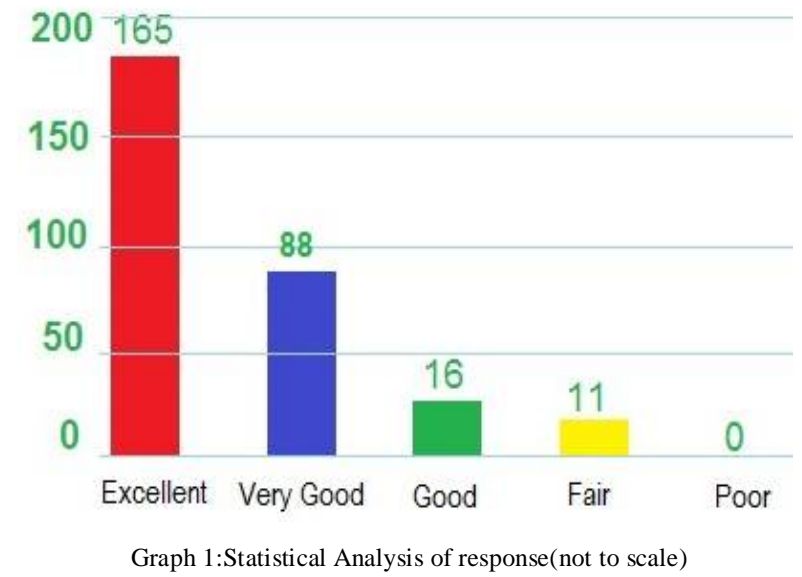

C. Reflections by Students

At the end of the workshop the students were given feedback forms to fill out their impression of the workshop. Below are some of the impressions as told by students:-
i. Itisvaluabletoknowtheaims\&objectives ofcollege.
ii. We would like to have more such workshops with more time.
iii. TheWorkshophelpstounderstandthebasicdifference between studying engineering and doing engineering.
iv. It helps in project based learning which we need more and more.
v. Such workshops provide a platform to apply our theory hand on

\section{Exhibition of Models}

On $26^{\text {th }}$ January, 2015 the participants of workshop 1 showcased their finished models to the college as part of exhibition conducted on eve of Independence Day celebration. Total of 9 models and 1 prototype was exhibited. And to keep the spirit going the best design was selected and awarded.

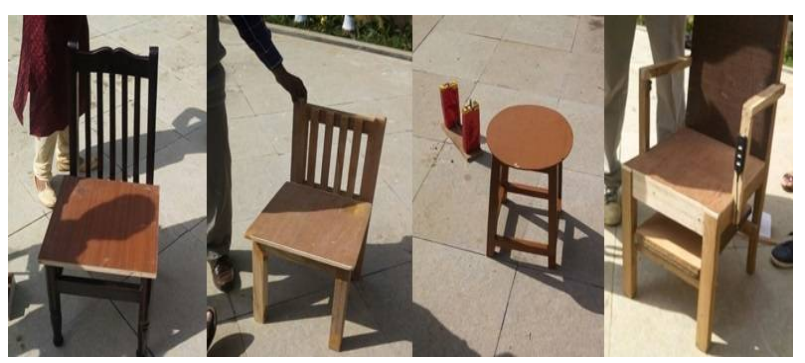

Figure 4.1: ExhibitedModels 1

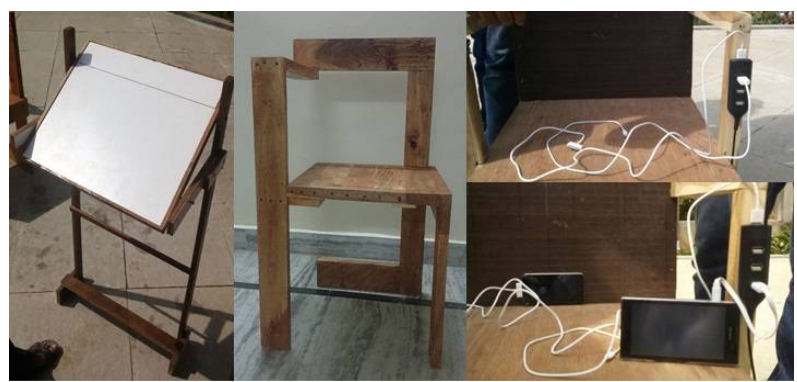

Figure 4.2 ExhibitedModels 2

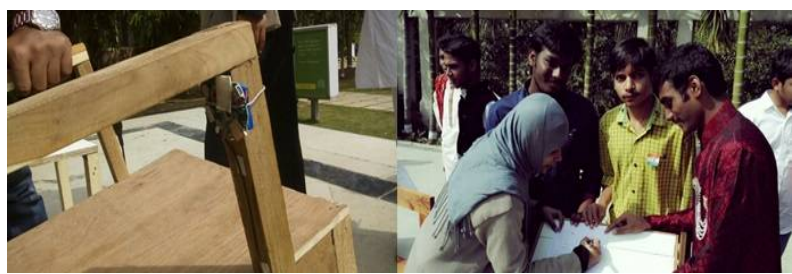

Figure 4.3 ExhibitedModels 3

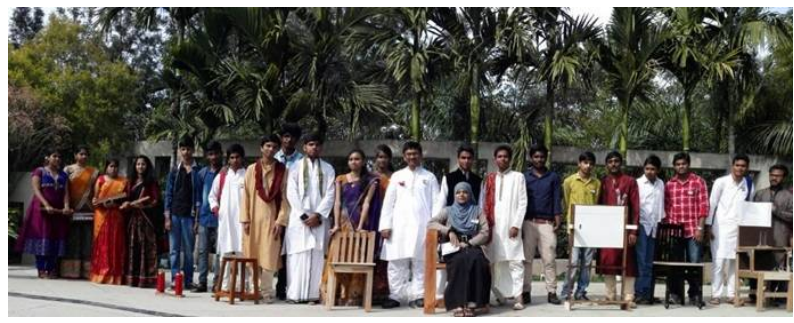

Figure 4.4ExhibitedModels 4 


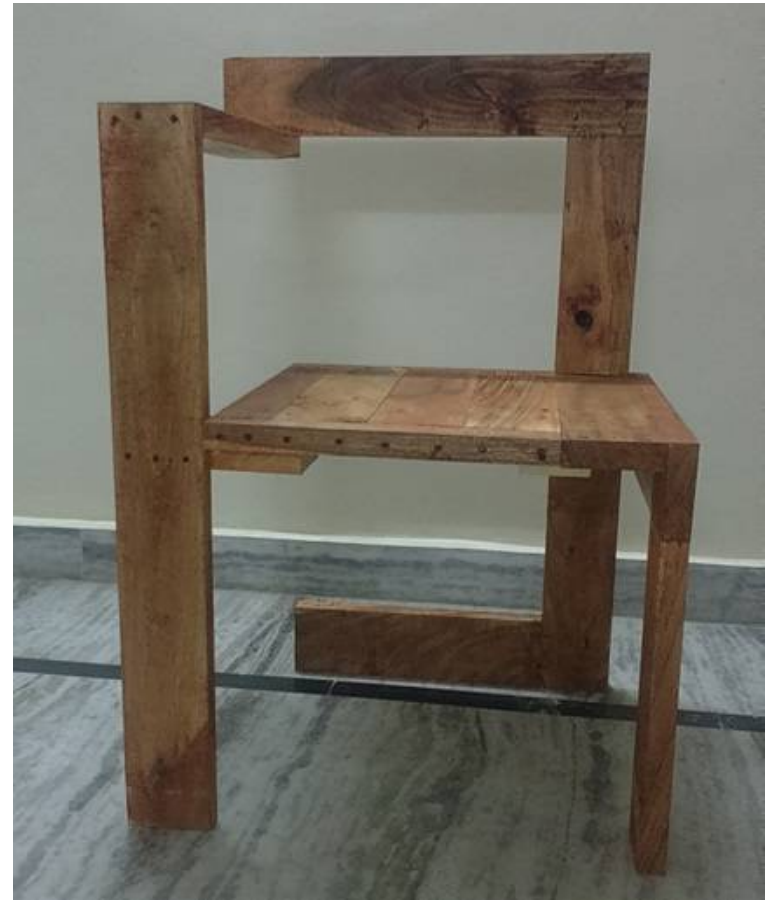

Figure 5: Best design

\section{Conclusions}

This workshops were a step towards doing engineering from studying engineering and was an initiative taken by the seniors who realised that studying engineering is not enough to become an engineer at the end of four years. More in depth and regular workshops can be conducted for students of all years to induce creativity and make it a habit to practice engineering on the field in practical scenarios. As the participating students of this workshop progress through their engineering more conclusions can be drawn and much more in-depth analysis of effects, variation in results and understanding of subject by students can be evaluated. All these results combined with proper teaching methodologies will then allow faculty to combine the modern as well as traditional methods of teaching, without compromise on quality and time.

\section{Acknowledgement}

The authors wish to thank the Management of Hyderabad Institute of Technology and Management for supporting this workshop and providing time from busy schedule of first year students. This work was successfully conductedbecause of the participation and helps fromsenior students and most importantly the above mentioned coauthors.

\section{Authors Profile}

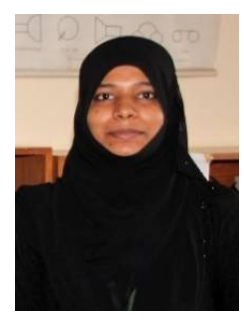

Ms. Azeem Unnisa is presently working as an Assistant Professor in the department of Electronics and Communication engineering,
atHyderabad Institute of Technology and Management (HITAM), Medchal, Hyderabad, India. She is having 3+ years of teaching experience. Her areas of interest are Robotics, Embedded Systems, Low Power VLSI, Wireless communication and Cryptography. She is a Microsoft certified educator. She is also a IUCEE-IGIP certified educator with distinction

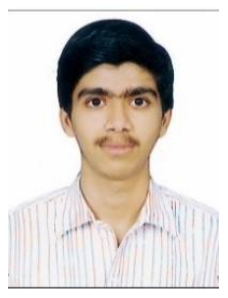

Ayush Kumar Dwivedi is presently pursuing Bachelor of Technology in department of Electronics and Communication Engineering from Hyderabad Institute of Technology and Management (HITAM), Medchal, Hyderabad, India. $\mathrm{He}$ is an aspiring young researcher working in the field of Digital Signal Processing and transforms. His areas of interest include Signal Processing for Communications and Security, Electromagnetic Noise and Interference, Navigational aids \& Radar and RF Communication.

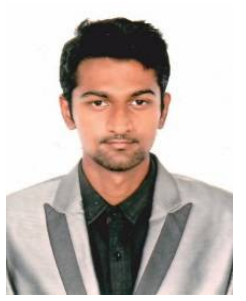

Saikat Saha is presently pursuing Bachelor of Technology in department of Electronics and Communication Engineering from Hyderabad Institute of Technology and Management (HITAM), Medchal, Hyderabad, India.He is a budding researcher in Technological field and Educational methodology. His areas of interests are Engineering Education Development, Robotics, Mechatronics, Programming, Electrical Circuit Designing, Image Projection, Image processing, RADAR, surveillance systems.He has been working with IUCEESPEED India student chapter since 2013 on development of Engineering Education. 